\title{
Editorial
}

\section{The Association of Bone and Joint Surgeons, Orthopaedia, and You}

\author{
Bert J. Thomas MD, Richard A. Brand MD, \\ Joseph Bernstein MD, Christian Veillette MD
}

Published online: 3 February 2009

(C) The Association of Bone and Joint Surgeons 2009

\section{The Association}

The Association of Bone and Joint Surgeons might be the most important orthopaedic organization you never heard of. The Association was formed in 1947 to advance the science and practice of orthopaedic surgery. For more than 60 years, it has promoted the creation, evaluation, and dissemination of new knowledge and facilitated interaction among orthopaedic surgeons. In 1953, it launched the publication you are now reading, Clinical Orthopaedics and Related Research. The Association also sponsors the annual ABJS Carl T. Brighton workshop and research prizes named after Nicolas Andry and Marshall Urist. There are currently 85 active members of the Association. Most hold academic appointments around the country; all, without exception, are committed to the Association's mission of creating, evaluating, and disseminating new knowledge.

We trust you know of the Association's current work. We are writing now to introduce its project for the future: Orthopaedia.

B. J. Thomas

Department of Orthopaedic Surgery, UCLA Medical Center, Los Angeles, CA, USA

R. A. Brand

Clinical Orthopaedics and Related Research,

Philadelphia, PA, USA

J. Bernstein $(\bowtie)$

University of Pennsylvania, 424 Stemmler Hall, Philadelphia, PA 19104-6081, USA

e-mail: orthodoc@uphs.upenn.edu

C. Veillette

Division of Orthopaedic Surgery Toronto Western Hospital,

Toronto, ON, Canada

\section{Orthopaedia}

In keeping with its mission of creating, evaluating, and disseminating new knowledge, the Association has launched a new Web site, Orthopaedia.com. The name Orthopaedia reflects "Orthopaedic + Encyclopaedia." The name Orthopaedia also echoes the title of Andry's classic text, the eponymous book of orthopaedics. We think of Orthopaedia as a collaborative orthopaedic knowledgebase: a wiki with the capacity for social networking, blogging, resource sharing, and research collaboration, among other functions.

\section{Wikis}

A wiki is a Web site that allows visitors to add, remove, and edit its content. Howard G. "Ward" Cunningham developed the first wiki in 1995 , but only recently have wikis proliferated. The most famous wiki is Wikipedia, the online encyclopedia and home to millions of reader-written articles. As a wiki, Orthopaedia sustains a "living textbook" of orthopaedic surgery and musculoskeletal medicine - a reference work under constant revision and improvement. The pages of this living text are subject to modification, but more importantly, readers can post entirely new entries, expanding the table of contents as our knowledge grows.

Pages on Orthopaedia can be read by any visitor, but to help ensure quality, posting (and revising) material is limited to members. Membership, in turn, is open to all physicians, scientists, medical students, and teachers around the world with an interest in musculoskeletal health.

On Orthopaedia, all contributions-additions, deletions and editorial changes-are attributed to the contributor. 
Signing one's words should limit the outlandish or offensive: with no cloak of anonymity, self-restraint should reign. Moreover, signatures identify the source of information for readers, who then can credit (or discount) what they read accordingly.

\section{Social Networking}

Orthopaedia community members are granted their own home pages: personal space to post information about themselves. (If the living text on Orthopaedia can be considered a musculoskeletal Wikipedia, these personal spaces and the social networking capabilities they offer represent our version of Facebook.) The data posted in these pages will of course enlighten readers about authors' credentials but also will inform the world at large about members and their accomplishments.

Many organizations offer home pages to their members, but as a worldwide musculoskeletal medicine community, Orthopaedia can serve as the central node of permanent personal spaces. That is, Orthopaedia is not the school from which you will graduate; it is not the residency program you will leave one day; it is not your current employer. And it certainly is not only North American. In sum, Orthopaedia supports an enduring, global network.

Resource Sharing, Blogging, Research Collaboration, and Much More

Orthopaedia was created to serve as a repository of shared resources, such as PowerPoint ${ }^{\circledR}$ lectures, videos, and radiographs. One particular depot of material is already taking form: The Orthopaedic Device Reference. The Device Reference is a searchable database of images and descriptions of implantable devices. Unlike other similar collections, this one is living: growing new content with the advent of new devices and elaborating on established content with members' comments on the listed devices.

Not every page on Orthopaedia is open for revision by the community. Obviously, members' home pages are under their exclusive control; so too are the areas for personal news and commentary. These pages then can be used by members to blog, for instance, or to engage in debates and discussions with other members. Job posting (and job hunting) is a natural extension of this feature, too.

Orthopaedia supports collaborative research. This goes beyond sharing manuscripts in preparation, an ideal wiki application, to recruiting colleagues for studies in general and conducting experiments in the realm of crowd intelligence in particular. Novel hypotheses can be presented on Orthopaedia Collaborators, a literal marketplace of ideas from which research teams may take root.

There undoubtedly are many uses for Orthopaedia not yet imagined. Fresh applications and novel technologies will be invented, and the good ones will thrive. In the coming months, we will outline our plan to foster innovation on Orthopaedia, centered on an award for Best New Use, but we encourage you to wonder: What can I do with a global network of colleagues that I could not do on my own?

\section{You}

Orthopaedia is a means, not an end. It is a method, not a finished product. The final shape of Orthopaedia will be fashioned not by design but by the actual activity of its members. Thus, there is a great unknown to be discovered: your role in Orthopaedia.

When The Association of Bone and Joint Surgeons was formed in 1947, it explicitly aimed to serve those who had something to say but no venue for saying it. In that sense, Orthopaedia is a proud continuation, 60 years later, of that initial mission.

We therefore invite you to join www.orthopaedia.com. Your account will let you establish a home page, empower you to post and revise content, and perhaps most importantly, grant you the ability to create a network of likeminded collaborators.

Please join the community of Orthopaedia users and shape the Future of Orthopaedic Knowledge Management at www.orthopaedia.com. 